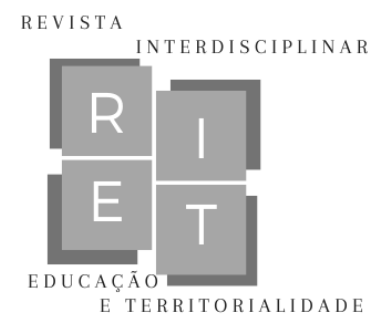

\title{
Saberes experienciais em tempos de pandemia: narrativas docentes
}

\author{
Experiential knowledge in times of pandemic: teaching narratives
}

Conocimiento experiencial en tiempos de pandemia: enseñanza de narrativas

Rodrigo Avella Ramirez

Unidade de Pós-graduação, Pesquisa e Extensão. Centro Estadual de Educação Tecnológica Paula

Souza (CEETEPS)

São Paulo, São Paulo, Brasil

E-mail: Roram100@hotmail.com

ORCID: https://orcid.org/0000-0001-8468-2851

\begin{abstract}
Alice Turibio Narita
Unidade de Pós-graduação, Pesquisa e Extensão. Centro Estadual de Educação Tecnológica Paula

Souza (CEETEPS)

São Paulo, São Paulo, Brasil

E-mail: aliceturibio@gmail.com

ORCID: https://orcid.org/0000-0001-9006-3176
\end{abstract}

Thiago Vieira de Matos

Unidade de Pós-graduação, Pesquisa e Extensão. Centro Estadual de Educação Tecnológica Paula

Souza (CEETEPS)

São Paulo, São Paulo, Brasil

E-mail: thiago.matos@cpspos.sp.gov.br ORCID: https://orcid.org/0000-0002-4113-2558

Resumo: Este artigo tem por objetivo interpretar como professores da educação profissional ressignificaram suas práticas docentes após terem suas rotinas e dinâmicas de aula transformadas pelo ensino remoto, adotado em meio à pandemia do Covid-19. Buscou-se fundamentação teórica em Tardif (2014) por ressaltar o valor da experiência profissional como fonte de saberes. Entrevistas com professores de várias instituições de educação profissional do estado de São Paulo, conduzidas por meio de roteiros semiestruturados e com foco em casos de ensino, constituem o eixo metodológico adotado. Os resultados indicam que, mesmo lecionando em instituições distintas, as percepções e atribuições de significados dos docentes diante deste novo modelo de aulas possuem denominadores em comum.

Palavras-chave: Narrativas. Pandemia. Saberes docentes.

Abstract: This paper aims to interpret how teachers from professional education have resignified their teaching practices after having their routines and classroom dynamics transformed by emergency remote teaching (ERT), adopted in the midst of the Covid-19 pandemic. Theoretical basis was sought in Tardif (2014) for emphasizing the value of professional experience as a source of knowledge. Interviews with teachers from various professional education institutions in the state of São Paulo, conducted through semi-

RIET-ISSN 2676-0355, Dourados, v. 2, n. 2, p. 115 a 128, jan./jun., 2021 


\section{Saberes experienciais em tempos de pandemia: narrativas docentes}

structured scripts and focused on teaching cases, constitute the methodological axis adopted. The results indicate that, even teaching in different institutions, the teachers' perceptions and assignments of meanings in face of this new model of classes have common denominators. Keywords: Narratives. Pandemic. Teaching knowledge.

Resumen: Este artículo tiene como objetivo interpretar cómo los profesores de educación profesional han vuelto a significar sus prácticas docentes después de que sus rutinas y dinámicas de aula se transformaran por la educación a distancia, adoptada en medio de la pandemia Covid-19. Se buscó una base teórica en Tardif (2014) para enfatizar el valor de la experiencia profesional como fuente de conocimiento. Las entrevistas a docentes de diversas instituciones de educación profesional del estado de São Paulo, realizadas a través de guiones semiestructurados y enfocadas en casos de enseñanza, constituyen el eje metodológico adoptado. Los resultados indican que, aun enseñando en diferentes instituciones, las percepciones y asignaciones de significados de los docentes ante este nuevo modelo de clases tienen denominadores comunes.

Palabras clave: Narrativas. Pandemia. Enseñanza del conocimiento.

Data de recebimento: $16 / 03 / 2021$

Data de aprovação: 10/06/2021

DOI: $10.30612 /$ riet.v\%vi\%i.14379

\section{Introdução}

A crise causada pelo COVID-19, doença causada pelo vírus SARS-CoV-2, espalhouse pelo mundo a partir de novembro de 2019 e, ainda que tenha sido desenvolvida a vacina para imunizar a população mundial, seu poder de transmissão continua massivo e crescente, pois a distribuição e planos de imunização estão sendo ainda implementados pelos governos de Estado ao redor do mundo. No caso brasileiro, medidas de isolamento social e "lockdown" têm sido impostas na tentativa de conter a transmissão comunitária do vírus, que, no momento em que esse artigo está sendo escrito, ainda está descontrolado e permanece pressionando os sistemas de saúde, que vêem seus leitos de clínica médica e unidades de tratamento intensivo completamente utilizados. Assim, além dos eventos de escala global, como as Olimpíadas, sofreram impacto aqueles de escala local, como campeonatos esportivos, de maneira que a aglomeração de pessoas foi amplamente desestimulada e tais medidas foram submetidas a todos os espaços que pudessem reunir muitas pessoas, inclusive escolas.

Deu-se início, nas instituições de ensino, a discussão acerca de como as atividades educacionais se desenvolveriam neste cenário. A medida em que as escolas não puderam retomar suas atividades presenciais, iniciou-se a busca por ferramentas que pudessem viabilizar as aulas de forma remota. Após um ano - as medidas de isolamento e quarentena começaram a ser implantadas em março de 2020 - muitas tentativas foram utilizadas pelas 


\section{Saberes experienciais em tempos de pandemia: narrativas docentes}

instituições de ensino na direção de tentar viabilizar os espaços de aprendizado para as plataformas digitais.

Esta transformação impactou a prática docente, as metodologias, as ferramentas de aula e até o raciocínio pedagógico do docente para que a aprendizagem acontecesse, agora, de forma virtual, onde a sala de aula não é mais um espaço físico, mas diversos. Baseando na teoria dos saberes de formação docente de Maurice Tardif, indaga-se o que o professor está aprendendo, em sua prática, neste momento de pandemia. O que vê hoje, em seu fazer pedagógico, que não via antes de as escolas serem fechadas? Nesse sentido, esse artigo procura compreender, a partir dos relatos de professores da educação profissional, como essas mudanças foram implementadas, percebidas e como influenciaram seu fazer pedagógico e de que maneira esses docentes puderam resignificar suas práticas na tentativa de manter.o exercício pedagógico vivo em meio ao que vem sendo chamada de a maior crise sanitária do novo século..

\section{Desenvolvimento}

Conforme afirma Ramirez (2014, p. 77), ao se considerar a atuação profissional como fonte, em si, de saberes, pode-se intuir que ensinar seja mobilizar saberes, utilizá-los. E ao mesmo tempo em que mobiliza seus saberes, o docente constrói outros, no seu dia a dia de trabalho, que agrega, paulatinamente, àqueles que possui. Portanto, contribuem para o seu desenvolvimento profissional o contato com os conteúdos da(s) disciplina(s), a metodologia, os planos e os currículos adotados pela instituição de ensino, bem como as relações sociais que estabelece no locus de trabalho, com seus pares, colegas e alunos. E podem, ainda, ser consideradas potencializadoras de seus saberes, as situações de aprendizagem que o docente elabora, bem como adversidades que enfrenta tanto na escola como na sociedade em que vive, que, de alguma maneira, impactam sua prática pedagógica.

A prática docente, quando considerada como prática social, historicamente construída, condicionada pela multiplicidade de circunstâncias que afetam o docente, a instituição, o momento histórico, o contexto cultural e político, realizar-se-á como práxis em um processo dialético que, a cada momento, sintetiza as contradições da realidade social em que se insere, e assim se diferenciará de uma prática organizada de forma a-histórica, como sucessão de procedimentos metodológicos (FRANCO, 2012 p. 203).

O contexto histórico em que se vive, marcado pela pandemia gerada pela COVID-19 que, de acordo com o Ministério da Saúde é uma doença causada pelo novo corona vírus, 


\section{Saberes experienciais em tempos de pandemia: narrativas docentes}

identificado na China em 2019, alterou, no mundo inteiro, o locus da prática docente impactando-a de uma maneira sem precedentes.

Recentemente, em dezembro de 2019, houve a transmissão de um novo corona vírus (SARS-CoV-2), o qual foi identificado em Wuhan na China e causou a COVID-19, sendo em seguida disseminada e transmitida pessoa a pessoa. A COVID-19 é uma doença causada pelo corona vírus, denominado SARS-CoV-2, que apresenta um espectro clínico variando de infecções assintomáticas a quadros graves. (BRASIL, 2020).

A pandemia fechou as escolas obrigando os professores a (re)construir o seu saber pedagógico a fim de prosseguir com a prática docente. Re(construir), pois, de acordo com Tardif (2014, p. 16), o saber do professor deve ser compreendido em íntima relação com seu trabalho na escola e na sala de aula. E, ainda, que esta relação, de seu saber com o trabalho, lhe fornece princípios para enfrentar e solucionar situações cotidianas. Porém, embora a pandemia não possa ser classificada como situação habitual, ela alterou as vidas humanas, impondo uma nova situação cotidiana. E, no que diz respeito aos professores, o novo normal impôs a virtualização da escola e o ensino remoto. Assim, como em Tardif (2002, p. 57), o trabalho, ao modificar o homem e sua identidade, modifica também o seu "saber trabalhar" de forma que a sua prática e seu encontro com a realidade da forma que se apresenta incrementa ao profissional e, consequentemente às organizações novos aprendizados e meios de exercer a sua atividade.

Considerando que o saber do professor traz em si mesmo as marcas de seu trabalho, que ele não é somente utilizado como um meio no trabalho, mas é produzido e modelado no e pelo trabalho (TARDIF, 2014 p. 17), indaga-se o que o professor está aprendendo, em sua prática, neste momento de pandemia. O que vê hoje, em seu fazer pedagógico, que não via antes de as escolas serem fechadas? E, aprofundando, o que poderá emergir como práticas que podem ser adotadas na direção de uma sala de aula que não mais se limita às fronteiras do espaço físico?

$\mathrm{Na}$ busca por respostas para estas perguntas, recorre-se à pesquisa narrativa por meio de entrevistas semiestruturada com professores de instituições de ensino técnico do estado de São Paulo.

A pesquisa narrativa pode ser desenvolvida a partir do contar e do vivenciar histórias. O "contar de histórias" se realiza quando o pesquisador ouve as histórias dos seus colaboradores sobre as experiências que eles vivenciaram. Esse "ouvir" pode ser entendido para além da escuta da fala, 


\section{Saberes experienciais em tempos de pandemia: narrativas docentes}

no sentido literal, ou seja, o pesquisador por se valer de textos escritos (autobiografias, documentos, cartas, diários, anotações, entre outros) compostos pelos participantes, nos quais são narrados os sentidos atribuídos sobre as experiências. Nesse caso, o pesquisador não presenciou, não observou ou não vivenciou as experiências junto com os participantes. A sua contribuição ocorre no momento do contar e construir sentidos a essas histórias (MARIANI, 2016, p. 115).

Entende-se que ao relatar suas experiências, as pessoas têm a oportunidade de refletir sobre seus comportamentos e atitudes e, assim, compor sentidos que se tornam significativos para elas. Pois, ao refletirem, organizam, problematizam e interpretam suas experiências de maneira que ao se tornarem significativas, tornam-se, também, formativas. Como afirma Tardif

O que nos interessa, justamente, aqui, são as relações entre tempo, trabalho e aprendizagem dos saberes profissionais dos professores de profissão que atuam no ensino primário e secundário, isto é, dos saberes mobilizados e empregados na prática cotidiana, saberes esses que dela provêm, de uma maneira ou de outra, e servem para resolver os problemas dos professores em exercício, dando sentido às situações de trabalho que lhe são próprias (TARDIF, 2002 p. 58).

Nesse sentido, o conhecimento advindo dessas experiências contribui para o aprofundamento da compreensão acerca de um determinado tema, em que uma história contada, ao ser extraída pelo ouvinte do contexto narrado, pode ser re-contextualizada em outras situações ou experiências, produzindo novas compreensões entre os contadores e os ouvintes (LIMA; GERALDI; GERALDI, 2015 p. 22).

Segundo Somekh,

o trabalho de narrativas e história de vida dá a oportunidade de reexaminar a pesquisa social reconhecendo a complexidade dos encontros humanos e incorporando a subjetividade humana ao processo de pesquisa (SOMEKH; LEWIN. orgs. 2015, p. 217).

Assim, ao se observar o cenário produzido pela COVID-19 ao redor do mundo, considera-se importante a colaboração que as experiências vividas pelos docentes podem trazer para o cenário educacional à luz de toda transformação decorrente do isolamento social, uma vez que o objetivo da análise narrativa é mostrar como as pessoas compreendem a narrativa vivida e como a narração desta experiência lhes dá condições de interpretar o mundo social e suas atuações dentro dele (SOMEKH; LEWIN. orgs. 2015, p.219).

É importante destacar, ainda, que segundo Altan e Lane (2018 p. 1), os professores são agentes de mudança na sociedade, pois têm maior influência no desenvolvimento dos alunos. Logo, espera-se que os professores estejam dispostos a lidar com as rápidas mudanças e as 


\section{Saberes experienciais em tempos de pandemia: narrativas docentes}

inovações do Século XXI. Tal disposição (atitude) dos professores também é importante para outros aspectos das experiências de aprendizagem dos alunos.

Portanto, conhecer como os professores da educação profissional têm lidado com as mudanças neste momento de pandemia é relevante uma vez que atitudes têm sido relacionadas aos comportamentos e crenças, e estas influenciam a prática docente tanto quanto os conhecimentos curriculares e todos estes saberes têm um impacto duradouro no processo de ensino e aprendizagem.

\section{Método}

O recorte teórico que se utilizou no presente estudo está amparado, também, no método de histórias de vida ou narrativas, em que os discursos acerca de uma determinada experiência carregam saberes de um determinado assunto a partir da vivência de uma pessoa ou grupo social, em que "o objetivo da história de vida é compreender a interação entre mudança social, vidas e ação de indivíduos e grupos"(SOMEKH; LEWIN. orgs. 2015).

Segundo Oliveira (2017), a relevância da pesquisa narrativa se confirma, pois,

No contexto nacional, o uso da Pesquisa Narrativa em educação se tornou um procedimento metodológico o qual possibilita trabalhar a dimensão subjetiva do sujeito. Assim, a pessoa passa a ser vista não apenas como um objeto a ser investigado ou analisado, mas sim, o próprio processo da investigação (OLIVEIRA. 2017, p.12155)

O contexto apresentado é o isolamento social, medida de contenção para evitar os avanços da pandemia causada pelo COVID-19. Para que se pudesse conhecer mais a fundo os saberes gerados nessa abrupta transformação global com efeitos, também, no âmbito educacional e para que se pudesse tirar dessa vivência aprendizado e reflexão, foram convidados docentes de instituições de ensino profissional, mestrandos pelo Programa de Pós Graduação do Centro Paula Souza - SP, que vivenciam os papéis de docentes e alunos em processos de ensino e aprendizagem no recorte aqui proposto.

Foram entrevistados, utilizando a plataforma Microsoft Teams, disponibilizada pela unidade de Pós-Graduação, Extensão e Pesquisa do Centro Paula Souza, docentes com diferentes formações, de três instituições de ensino profissional, localizadas na cidade de São Paulo. As entrevistas foram realizadas de forma separada, conduzidas pelos autores e utilizou-se uma pesquisa qualitativa, com perguntas estruturadas e direcionadas para se conhecer as experiências e os saberes gerados pelo docente neste novo cenário global. 


\section{Saberes experienciais em tempos de pandemia: narrativas docentes}

\section{Resultados e discussões}

A pandemia trouxe desafios inesperados. Com ela foi preciso adequar as práticas educacionais para que o processo de aprendizagem não parasse, o que causaria grande prejuízo pedagógico aos estudantes e ao país. Porém, a adaptação do ensino presencial para o ensino na modalidade remota provou-se desafiadora para todos os atores do contexto educacional, sobretudo os docentes.

Em uníssono, os relatos dos docentes arguidos sinalizam o grande impacto que essa migração da sala de aula presencial para a modalidade remota causou em suas rotinas, bem como no modo como estruturam suas atividades de docência.

As falas a seguir apontam como primeira necessidade ao processo de adaptação para a modalidade de ensino remoto, tanto dos alunos como dos docentes, o acesso e o uso da tecnologia.

Voltando para a questão do isolamento decorrente da pandemia, isso modificou muito [minhas aulas] porque, o que acontece? Eu não tenho mais essa possibilidade de controlar, né? De orientar, de sugerir o trabalho em equipe porque nem todos têm acesso à internet. Eu tenho uma turma que $30 \%$ da turma desistiu. É, 30\%! Eram trinta e poucos alunos e na verdade ficaram 20. E aí, o que acontece? Desses 20, 12 assistem às aulas; 10 às vezes; 6 às vezes, né? O máximo são 12, 13 alunos. Então, assim, você perde o controle, e não tem mais. Ele vai entrar [na aula] no seu tempo; as aulas são gravadas. (Docente F. R.)

Olha, no começo foi mais complicado porque os alunos falavam 'não tenho acesso, onde eu moro não chega o sinal, não tenho equipamento', foi meio complicado. Agora está melhor porque quando nós começamos a fazer isso lá em abril, a gente já começou a explicar para eles como é que eles iam fazer quando estivessem em casa, né? Mas, também, tem aqueles alunos que começaram a se sentir psicologicamente abalados com relação a isso. Pelo menos é o que me demonstraram com o que eles comentavam com a gente, falando que não conseguem se concentrar, não conseguem entrar na aula, ficam muito preocupados. Então foi bem complicado no começo, agora está melhor, mas ainda tem aqueles alunos que falam que não conseguem. (Docente A. S.).

O saber docente pode ser analisado a partir da relação com seu trabalho na escola e na sala de aula, tanto presencial quanto virtual. Esta relação, de seu saber com o trabalho, lhe oferece meios para enfrentar e solucionar situações cotidianas.

[No começo] foi um grande desafio para mim; foram dois polos. O primeiro foi realmente criar paz. Tudo aqui [na instituição] é presencial e 


\section{Saberes experienciais em tempos de pandemia: narrativas docentes}

até então eu nunca tinha trabalhado dessa forma remota, né? Eu tentei fazer essa operação de acordo com a forma como eu já havia aprendido fazendo cursos online. Mais uma vez eu trago para [a docência] a forma como eu aprendi. Isso da maneira como eu aprendi, a forma como eu fiz minha pósgraduação e duas outras pós-graduações, e até faço diversas ações do Centro Paula Souza e outros cursos. Eu gosto muito de aprender e com essa nossa rotina doida e como a gente está ali, é tão maravilhoso. Vamos dizer que é legal estudar de forma remota on-line, quando começou a pandemia, eu teria que fazer isso. (Docente B. F.).

Os alunos transpareçam seu descontentamento pela falta de acesso à tecnologia, o que em alguns relatos levou ao aumento da evasão nas aulas remotas. Alguns haviam se habituado ao ensino presencial e às interações que uma aula presencial nos permite e agrega à construção do conhecimento.

Os educadores, por sua vez, ao perceberem a dificuldade de adaptação dos alunos perante as aulas remotas, passaram por um processo de autorreflexão das suas práticas a fim de criar novas estratégias de ensino para a modalidade remota, aprendendo com a exploração de novas ferramentas digitais que seriam úteis para o ensino na modalidade remota, ou seja, desenvolveram novos saberes experienciais, como pode ser percebido no relato abaixo.

Mas, o que eu tenho procurado fazer? Muitas atividades durante a aula, eu fui buscar no assistente Google. Procura no Google, no YouTube, porque você tem que aprender. Então, tive que aprender a trabalhar com a ferramenta do Teams; e eu tive que ensinar os meus alunos a trabalharem. Alguns não conseguiram e desde o começo da pandemia desistiram porque acharam muito difícil. Por mais que eu tentasse, eu não conseguia. Os demais docentes também não. E aí, o que acontece? Você vai perdendo. E a aula pra mim ficou muito chata porque eu ando durante a aula, eu converso, eu peço exemplo, eu faço brainstorming, eu faço um monte de coisa. E aí o que eu venho tentando fazer? A mesma coisa de forma remota. Então, eu abro lá, o Mentimeter, antes de começar a aula ela, e pergunto: Pessoal, a aula de hoje é sobre tal tema, o que vocês acham a respeito? Compartilho com eles o link do Mentimeter através do chat. Eles respondem: Está difícil. Tenho dúvida ainda. E aí, com base em todas as argumentações, todas as sugestões, ideias e críticas, eu início a aula. E aí vem a parte conceitual que, não tem como, não dá pra você não passar o conceito, né? E fica chato porque eles ficam ouvindo. Aí, de slide a slide, eu brinco; eu abro, peço para eles falarem: Fulano, o que você achou disso? Eu chamo pelo nome porque tem gente aqui que liga e fica pra lá; que está participando e não está presente. Eu já peguei aluno assim. Eu chamo, chamo, e o aluno não responde. Então, eu faço muito isso. Eu chamo um por um todas as aulas e faço perguntas direcionadas. E ao final, nós muitas vezes voltamos pro Mentimeter até pra ver o que mudou, se eles compreenderam. Eu faço exercícios no Google, né? No Google Forms para eles responderem. Na hora eu utilizo o Socratic, utilizo o Kahoot, eu faço tudo em todas as aulas porque fica muito chato uma aula conceitual. Por mais que eles deem exemplos, por mais que eles façam, que participem, 


\section{Saberes experienciais em tempos de pandemia: narrativas docentes}

né? E você sabe quais são os [alunos] que participam. E fora isso, eu gravo a aula e às vezes baixo pro YouTube e compartilho o link da aula, mais o link do vídeo, mais um material de aula no Google Classroom. Porque, aí aqueles que não puderam assistir naquele momento assistem depois. Estou com bastante dificuldade em trabalhos em equipe, que eu fazia muito em sala de aula, agora, por conta da distância deles, né? da internet, eu já consigo fazer trabalhos com no máximo 2, 3 alunos, né? E a maioria individual. (Docente F. R.).

O que se percebe, pelo exposto acima, é que os saberes e as competências dos professores estão em constante transformação e foram completamente ressignificadas no período em que esses precisaram desenvolver novas habilidades para adaptar seu trabalho o fazer docente - ao período de pandemia.

Além das dificuldades com o desenvolvimento dos saberes técnicos que o momento requer, neste relato fica evidente o isolacionismo da profissão docente, ou seja, não há um trabalho coletivo e colaborativo entre os docentes.

Bom, como eu já sou um fuçador nato, eu me dei bem com relação a essas novas atividades aí. O SENAI também nos amparou muito bem, porque já começou lá em abril a fazer o Webinar e explicar para gente o que a gente ia fazer. Os professores da escola que já utilizam essas ferramentas se dispuseram a explicar para gente como a gente faria. Então, a gente teve um amparo bom em relação a isso e a qualquer momento a gente pode [perguntar]: Eu estou com uma dúvida aqui. o que vocês podem fazer? A gente manda no grupo e resolve na hora, né? Então, a gente está se virando bem com relação a isso. Eu não sei como é que estão os outros professores aí fora, mas a gente tá se dando bem. Então, tenho usado bastante o Teams, tenho usado Forms, tenho usado OneDrive, tenho feito vídeos. (Docente A. S.).

Por outro lado, o relato acima traz uma situação oposta, na qual há um trabalho colaborativo no desenvolvimento e na troca de experiências.

Virei um especialista em editar vídeos agora, utilizando, por exemplo, pego lá um link de um vídeo do Telecurso, e aí eu tenho que colocar no chat, colocar na tela, e disponibilizar no WhatsApp também, para que eles consigam acompanhar. 'Você tem três lugares aí para clicar e assistir esse vídeo. Vou dar 30 minutos para você assistir.' A gente retorna, fica discutindo. Assim, a gente tem que agir assim, então, para não ficar aquela aula muito maçante, teórica. Você dá uma atividade ali de uma meia hora, uma teoria de uma meia hora, passa lá uma atividade para eles fazerem, eles não assistem. 'Com esse vídeo, eu vou disponibilizar um questionário para responder, veja essa demonstração que vai ser dada no vídeo e aí a gente vai discutir o assunto. Com essas informações que foram passadas até agora, faça um checklist das informações principais que irão ser verificadas lá na prática. Vamos fazer um planejamento do que a gente vai precisar para quando vocês voltarem a gente revisitar'. Então, são essas as 


\section{Saberes experienciais em tempos de pandemia: narrativas docentes}

coisas que nós estamos desenvolvendo. Agora, também tinha coisa que a gente utilizava pouco. E agora dá para a gente dar uma atenção maior, não passar muito corrido com o aluno. Por exemplo, quando você ia falar para ele de alinhamento e de eixos co-lineares na mesma linha, existe várias técnicas e a gente ficava só em uma porque a gente ia aplicar, e agora dá para gente falar de todas. Então se o aluno chegar lá e for diferente, ele sabe por quê. Pode ser que ele não sabia fazer porque ele não executou, mas ele sabe o que está sendo feito, e sabe o que deveria fazer. Mas a gente ainda está tentando resgatar a prática, porque, por exemplo, os alunos que se formaram nesse meio termo, estão lá na escola porque algumas competências não foram trabalhadas e eles precisam fazer essa prática, executar essa prática. Para que eles não saiam sem essa informação, os alunos do $4^{\circ}$ termo que terminaram em julho, eles estão lá terminando as práticas que eles não fizeram, mas só eles. (Docente A. S.).

O primeiro ponto desafiador foi o objetivo, como vou traduzir aquela minha aula para o formato on-line. Aí eu senti um agravante porque as minhas aulas são todas práticas, são aulas práticas, eu dou aulas no laboratório, dando aula de robótica. Agora eu dou aula de máquinas elétricas, então obviamente existe a necessidade de o aluno mexer. Então [a prática] é limitada. (Docente B. F.).

As falas desses docentes mostram como cada um está lidando com esses saberes e com a aplicação desses novos saberes, enquanto um está conseguindo aplicar seus novos saberes com essa nova realidade, o outro demonstra frustração por não estar conseguindo desenvolver habilidades nessa nova modalidade.

Decorrente do esforço por parte do educador de criar novos saberes para dar continuidade ao processo de aprendizagem, houve uma reinvenção do processo educacional, resultando assim em uma inovação inesperada não só na apropriação das ferramentas digitais aplicadas à educação, mas no processo de ensino e aprendizagem em si.

O aumento da carga de trabalho docente foi um ponto contundente nos relatos.

Então, eu trabalhava a minha carga horária, no SENAC era 3 horas e meia por noite, e agora eu trabalho o dia inteiro porque eu tenho que modificar todas as minhas aulas. Eu tenho que modificar, aí eu testo um modelo. Não dá certo. No dia seguinte, eu tenho que modificar para adaptar àquilo que eles compreendem, para que eu me assegure de que eles efetivamente absorveram a aprendizagem. Então, assim eu percebo o que eles estão compreendendo. Eu não fico com uma forma só de avaliação. Eu testo várias durante a aula e depois da aula, e na próxima aula retorno os pontos. Então, é difícil, cansativo, mas gratificante por perceber que assim, dependente de todo o seu trabalho, como você consegue ter um resultado. (Docente F. R.).

Por exemplo, fizemos grupos de WhatsApp, se ele não consegue entrar [na aula] manda pelo WhatsApp, aí a gente entra pelo Teams, coloca lá o email deles e convida eles para aula, aí mesmo que ele não tenha um 


\section{Saberes experienciais em tempos de pandemia: narrativas docentes}

computador e entre pelo celular, normalmente todos os alunos têm celular né, eles baixam o aplicativo Teams e pelo menos conseguem acompanhar a aula. Mesmo assim, eu estou gravando a aula e estou disponibilizando a apresentação de slides, estou disponibilizando a aula gravada, estou dando um tempo maior para eles entregarem as atividades, e ainda tenho que ficar o tempo inteiro mandando mensagens e respondendo. Na verdade, nosso serviço não dobrou, triplicou. (Docente B. F.).

Os docentes não se opõem a desenvolver novos saberes, porém existe uma pressão temporal para que esses saberes sejam desenvolvidos muito rapidamente, o que afeta o próprio desenvolvimento profissional dos docentes. As situações de aprendizagem que os docentes elaboram podem ser consideradas potencializadoras de seus saberes, bem como adversidades que enfrentam tanto na escola como na sociedade em que vivem, que, de alguma maneira, impactam sua prática pedagógica.

Alguns relatos mencionam o impacto da pandemia na vida familiar do professor.

Tem outras plataformas aí presente para minha filha, e agora ela está em casa também. E quando eu estou em casa, tenho que acompanhar a aula dela, se ela está fazendo direitinho. Então, tem tudo isso aí, que eu acho que agora está difícil porque temos que aprender tudo, mas no futuro vai facilitar nossa vida. As mudanças acontecem, assim a gente tem que entender sempre, pensar que o que o acontece é para melhorar. (Docente A. S.).

Nesse caso, Tardif (2002) afirma que "o tempo de aprendizagem do trabalho confunde-se muitas vezes com o tempo da vida: o trabalho é aprendido através da imersão no ambiente familiar e social” e, nesse caso específico, considerando como pano de fundo todo o cenário mundial aqui já apresentado, o trabalho docente, sua aprendizagem e reflexão sobre o que se faz se funde e se mistura ao seu cotidiano mais particular: a sua própria casa e família, onde o trabalho que executa se funde e mistura de forma transversal e múltipla ao dia a dia do seu ambiente privado.

O saber do professor traz em si mesmo as marcas de seu trabalho, que ele não é somente utilizado como um meio no trabalho, mas é produzido e modelado no e pelo trabalho, como afirma Tardif.

Nós já temos as aulas, nós já temos a experiência, nós já temos a didática de sala de aula. Então, assim o que mudou? Eu aprendi, eu cresci, eu estou tendo que ser melhor a cada dia porque a cada aula que eu vou e que eu percebo que fica aula ficou parada, eu fico chateada. Poxa vida, amanhã eu tenho que pensar em algo melhor. Então, por isso minhas horas triplicaram. 
Mas, ao final eu tenho certeza que eu vou sair muito melhor do que eu entrei, com muito mais expertise em vários assuntos.

[...] então, os saberes são desenvolvidos na sala de aula e com aquilo que você traz na sua bagagem, seja ele de onde for. Seja ele pedagógico, seja ele corporativo ou seja ele de onde for. Os saberes você desenvolve na sala de aula de frente para o aluno e de acordo com cada aluno porque cada um aprende de um jeito.

Então, assim eu preciso mesclar uma pluralidade mesmo de saberes porque eu tenho que aprender a parte tecnológica, eu tenho que aprender como nesse momento, em que eu não posso me aproximar do aluno fisicamente, eu faço para que ele continue gostando da minha aula, para que ele continue participando. Então, assim, Elda, não existe um saber. Eu acho que nesse momento, todos os saberes se afloraram. Eu acho que, acima de tudo, é a resiliência porque é muito difícil para o aluno, mas é muito chato, é difícil para o professor ficar ali, sabe, explicando um conceito, olhando para o computador. (Docente F. R.).

Pelo exposto acima observa-se o que afirma Tardif (2002 p. 66) quando expõe que o ato de narrar a experiência vivida pelo professor, lhe confere a capacidade de revisitar o passado, fazer conjecturas e antever situações futuras.

\section{Considerações finais}

Os relatos colhidos no processo de construção desse artigo corroboram a teoria inicial aqui apresentada de que os docentes desenvolvem saberes na prática pedagógica. Contudo, esses saberes não são isentos de dúvidas, incertezas e angústias. Evidenciou-se que as instituições de educação profissional pesquisadas, através dos relatos de seus docentes, estão tomando ações para adaptar-se ao ensino remoto, porém em graus e níveis diferentes.

A situação de ensino remoto chegou e pode ter longa duração, de fato, já perdura por mais de um ano e, apesar de já terem sido feitas tentativas de retorno à modalidade presencial na iniciativa pública e privada, os professores estão conscientes disso e não se eximem de sua responsabilidade de desenvolver novos saberes, porém desejam e necessitam de mais apoio e tempo. Não são somente os alunos os necessitados; os docentes também têm suas necessidades a serem minimamente atendidas.

Uma forma de obter sucesso, apesar de estar sendo vivenciado um cenário de distanciamento social, é o trabalho colaborativo, conforme relatam os docentes. Ou seja, mesmo sendo necessário isolar as pessoas em uma situação caótica, como a da pandemia, é preciso mantê-las conectadas e em constante troca. É importante que se criem novos espaços de desenvolvimento profissional docente onde os saberes teóricos experienciais e pedagógicos que compõem a base do conhecimento profissional docente possam se 


\section{Saberes experienciais em tempos de pandemia: narrativas docentes}

desenvolver e se instaurar. Após várias experimentações que vêm sendo feitas nesse período de trabalho remoto, surgem novas dinâmicas de trabalho pedagógico, as quais necessitam de observação, análise e discussão , a fim de que se possa manter a atividade educacional em operação ao mesmo tempo que se preserva a vida e a saúde das pessoas de forma geral.

De maneira que já pode-se discutir a implementação do ensino híbrido e a extrapolação do espaço da sala de aula física para as plataformas digitais, entretanto, não se pode esquecer da figura do professor, que permanece mediando os fenômenos da aprendizagem. Há de se pensar, desde a estrutura física que será a esse docente disponibilizada até os mecanismos de proteção de sua salubridade. É importante ressaltar que as entrevistas coletadas para esse artigo foram realizadas na fase inicial da quarentena, quando a migração para as plataformas digitais ainda estava acontecendo nas escolas e muitas dessas questões aqui apresentadas estavam aparecendo em forma de suposições, medos e palpites que, de certo ponto de vista, foram se confirmando em maior ou menor proporção.

Assim, esse estudo oferece um ponto de contribuição para compreensão de um momento histórico que ainda se vive, a partir da experiência de docentes que vêm enfrentado os desafios e novas realidades que se apresentam. A esse trabalho, somam-se dezenas de outros, narrativos ou não que procuram contribuir para o desenvolvimento da própria educação e, consequentemente, da vida humana em suas múltiplas realidades.

\section{Referências}

ALTAN, S.; LANE, J. F. Teacher's narratives: A source for exploring the influences of teacher's significant life experiences on their dispositions and teaching practices. Disponível em <https://www.sciencedirect.com/science/article/abs/pii/S0742051X17316396>. Acesso em 15 ago. 2020 .

BRASIL. Ministério da Saúde. O que é COVID-19. Brasília, 2020. Disponível em < https://coronavirus.saude.gov.br/sobre-a-doenca\#o-que-e-covid>. Acesso em 15 ago. 2020.

FRANCO, M. A. R. S. Pedagogia e prática docente. 1. ed. São Paulo: Cortez, 2012.

LIMA, M. E. C. C.; GERALDI, C. M. G.; GERALDI, J. W. O trabalho com narrativas na investigação em educação. Educação em Revista| |v.31|n.01|p.17-44| Belo Horizonte: JaneiroMarço 2015.

MARIANI, F. A pesquisa narrativa na formação de professores: aproximações que se potencializam. Disponível em <http://dx.doi.org/10.18593/r.v41i1.8878>. Acesso em 15 ago, 2020.

OLIVEIRA, L. D. G. C. Pesquisa narrativa e educação: algumas considerações. EDUCERE XIII CONGRESSO NACIONAL DE EDUCAÇÃO. 2017. p. 12146 - 12159. 
RAMIREZ, R. A. Histórias de vida na formação do professor. São Paulo: Centro Paula Souza, 2014.

SOMEKH, B.; LEWIN, C. Orgs. Teoria e métodos de pesquisa social. Petrópolis, RJ: Vozes, 2015.

TARDIF, M. Saberes docentes e formação profissional. 17. ed. Petrópolis, RJ: Vozes, 2014 